\title{
TURKELS - A TURKIC FAMILY IN THE BYZANTINE CIVIL SERVICE
}

\author{
Andrey Yu. Vinogradov \\ National Research University Higher School of Economics, Moscow, Russian Federation \\ Denis V. Kashtanov \\ Independent Researcher, Moscow, Russian Federation \\ Viktor N. Chkhaidze \\ Institute of Archaeology of the Russian Academy of Sciences, Moscow, Russian Federation
}

\begin{abstract}
Introduction. The paper considers the two Byzantine lead seals of the second half of the $11^{\text {th }}$ century, the owner of which was a translator (ermeneutes) with a non-Christian name Turkeles. Analysis. The correct reading of the owner's name was possible by comparing the sigillographic texts with the inscription on a silver bucket found in Perm region (Russia). This richly ornamented vessel made in the last third of the $11^{\text {th }}-$ $12^{\text {th }} \mathrm{c}$, belonged, according to the inscription, to a Christian person called Theodore Turkeles. The most probable etymology of this very rare name is Turkic. Because both seals originate from the territory of the Old Rus, we can suppose that he was involved in the northern policy of Byzantium. Results. It can be assumed that the owner of the seal, Turkeles, became the first Rhomaios in his family, entering the service of the Emperor as a translator from Turkic languages. The owner of the bucket, Theodore was called by the second name Turkeles, either from his father or as a family name. Since no other Turkeles is attested in the Byzantine sources, the bearers of this name were not very successful in cultivating their family tree, and the patronymic could simply not have time to turn into a family nickname.
\end{abstract}

Key words: history of Byzantium, Byzantine families, Byzantine seals, iconography, prosopography.

Citation. Vinogradov A.Yu., Kashtanov D.V., Chkhaidze V.N. Turkels - a Turkic Family in the Byzantine Civil Service. Vestnik Volgogradskogo gosudarstvennogo universiteta. Seriya 4. Istoriya. Regionovedenie. Mezhdunarodnye otnosheniya [Science Journal of Volgograd State University. History. Area Studies. International Relations], 2020, vol. 25, no. 6, pp. 150-159. (in Russian). DOI: https://doi.org/10.15688/jvolsu4.2020.6.11

\section{ТУРКЕЛЫ - ТЮРКСКАЯ СЕМЬЯ НА ВИЗАНТИЙСКОЙ СЛУЖБЕ}

\section{Андрей Юрьевич Виноградов}

Национальный исследовательский университет «Высшая школа экономики», г. Москва, Российская Федерация

\section{Денис Викторович Каштанов}

Независимый исследователь, г. Москва, Российская Федерация

\section{Виктор Николаевич Чхаидзе}

Институт археологии РАН, г. Москва, Российская Федерация

Аннотация. В работе рассматриваются две византийские печати второй половины ХІ в., владельцем которых являлся переводчик (ерминевт) Туркел. Правильно прочитать имя владельца позволило обращение к найденному в Пермской области серебряному ковшу последней трети XI - XII в., владельцем которого был 
Феодор Туркел. Наиболее вероятная этимология имени - тюркская. Находка обеих печатей Туркела на территории Древней Руси говорит в пользу его работы на северном направлении византийской политики. Можно полагать, что Туркел стал ромеем в первом поколении, поступив на службу императору в качестве переводчика именно с тюркских языков. Владелец ковша Феодор именовался вторым именем Туркел, которое либо принадлежало отцу, либо являлось фамильным. Так как никаких других Туркелов в византийских источниках найти не удалось, носители этого имени были не слишком успешны во взращивании своего фамильного древа - семейное имя быстро сошло с исторической сцены.

Ключевые слова: история Византии, византийские фамилии, византийские печати, иконография, просопография.

Цитирование. Виноградов А. Ю., Каштанов Д. В., Чхаидзе В. Н. Туркелы-тюркская семья на византийской службе // Вестник Волгоградского государственного университета. Серия 4, История. Регионоведение. Международные отношения. - 2020. - Т. 25, № 6. - С. 150-159. - DOI: https://doi.org/10.15688/jvolsu4.2020.6.11

Первое поколение все еще имеет нравы жизни на открытом пространстве с ее суровостью и дикостью: эти люди испытывают лишения, отважны, хищны, участвуют в общей славе... Второе поколение благодаря владению и благополучию живет не на открытом, а на огороженном пространстве, не в лишениях, а в роскоши и изобилии, оно не соучаствует в общей славе... А третье поколение забывает эпоху жизни на открытом пространстве, как будто той и не было [9, с. 210].

Введение. Изучение родов и фамилий одно из самых перспективных направлений византийской просопографии. Благодаря введению в научный оборот большого количества нового материала, прежде всего сфрагистического и эпиграфического, становится возможным проследить судьбу многих византийских семей, как крупных и знатных, так и мелких и малозаметных. Такого рода исследования опираются на материал различных дисциплин, и именно на их пересечении проступают следы прежде неизвестных родов, одному из которых и посвящена эта статья.

Методы. Не так давно был опубликован византийский моливдовул [16, с. 124-125, рис. 1], найденный в 2016 г. близ с. Григорово ЮрьевПольского района Владимирской области (хранится в Новгородском музее-заповеднике) (рис. 1, a). Однако первоначальное прочтение имени его владельца ('Ікє $\lambda \eta \dot{\omega}-$ «Икелий») оказалось неверным. Кроме того, стало известно, что в частной коллекции хранится другой экземпляр печати (рис. 1, б), которая происходит, по всей видимости, с территории Украины.

По этой причине возникла необходимость вновь вернуться к указанному памятнику с учетом новых данных и поставить его в более ши- рокий контекст. Методологической основой для этого является междисциплинарный комплексный подход, предусматривающий использование сравнительного анализа сфрагистических, иконографических, эпиграфических и иных категорий памятников. Надеемся, что наши наблюдения послужат небольшим, но полезным дополнением к уже имеющимся данным по целому ряду сторон византийской жизни.

Анализ. Оба экземпляра исполнены одной парой матриц, поэтому описываем их суммарно. Печати (рис. $1, a-\sigma)$ несут на аверсе погрудное изображение Богородицы, которая держит обеими руками диск с изображением Христа - тип Никопеи. Ее лицо - грубое, одутловатое, совершенно лишено изящества. По сторонам - колончатая легенда:

$+M H P-\Theta V|| \Theta \in|O C| K \in-\Pi A|C T| O C=$

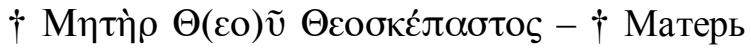
Божия Феоскепастос.

На реверсе печати читается заключенная в ободок пятистрочная надпись: $+\Theta K \in R O|T \omega C \omega \Delta U|$ TUPKEAH | EPMHNE |

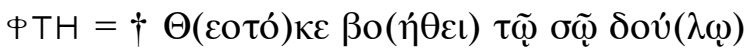

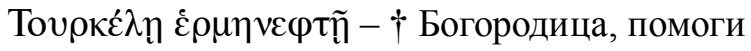
своему рабу Туркелу переводчику.

Размеры печати - вполне рядовые (диаметр - около 16 мм, толщина - 3 мм, вес - 6 г).

Изображение Богородицы Никопеи на печатях стало особенно популярным во второй половине XI века [30, S. 549-564; 31, S. 4143]. С такой датировкой полностью согласуется палеография надписи - начертания отдельных литер $(\forall, K, \Delta)$ также заставляют относить моливдовул к тому же времени [28, p. 167,169 , № 31, 44, 59].

Эту печать выделяют на общем фоне две интересные детали. 


\section{ВИЗАНТИЙСКАЯ СФРАГИСТИКА}

Во-первых, насколько мы можем судить, она демонстрирует самое раннее употребление весьма редкого эпитета «Феоскепастос». Судя по изображениям поздне- и поствизантийского времени, он мог прилагаться к любому из основных иконографических типов Богородицы [20, p. 121-224]: Оранта [22, p. 212-213, № 1295], Одигитрия [13, с. 23-29; 14, с. 126-127; 37, с. 395, 405], Умиление [26, б. 160, № 38].

Вторая особенность - написание долж-

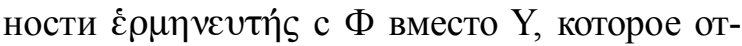
ражает завершение консонантизации дифтонга $\varepsilon v[35$, p. 22-24]. Несколько неожиданно видеть такое орфографическое отклонение на печати переводчика, однако следует помнить,

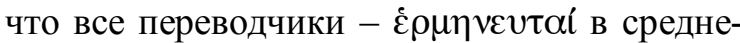
византийских источниках упоминаются в контексте устного, а не письменного перевода. Примечательно, что черты обиходной речи проступают и на печати коллеги Туркела, Иоанна [22, p. 232, № 470].

Корпус переводчиков, входивший в ведомство логофета дрома, играл важную роль в византийской дипломатии $[5$, с. $54-58 ; 24$, p. $8-10 ; 16$, с. $125-126 ; 17$, c. $56-57 ; 18$, c. $111-$ 112]. Переводчики (ерминевты и диерминев$m b l)$ выполняли разнообразные задачи: устный и письменный перевод, сопровождение посольств в империи и за рубежом. Помимо греков и латинян, нам известны скандинавские, арабские и - что особенно важно для нас тюркские переводчики [23, p. 230]. Впрочем, источники о деятельности переводчиков в Империи крайне фрагментарны. Если брать только сфрагистические свидетельства, то до настоящего времени для огромного периода VI-XIII вв. было известно всего 13 печатей переводчиков $[5$, с. $54-58 ; 15$, с. $8-10 ; 16$, c. $125-126 ; 17$, с. $56-57 ; 18$, с. $111-112]$. Поэтому каждая новая находка представляет исключительный интерес.

Второй раз имя «Туркел» встречается на серебряном ковше из Эрмитажа (инв. № $\omega$ 1207) (рис. 2). Он был найден до 1949 г. около деревни Пеняхино Соликамского района Пермской области [1, л. 46-47, фото 26; 2, с. 94, рис. 26, 1-7] (ныне не существующая деревня находилась на левом берегу рек Камы и Вишеры недалеко от их слияния) и вошел в состав открывшейся в 1956 г. византийской экспозиции Эрмитажа [3, с. 344].
Ковш изготовлен в виде плоской чаши, ручка и ножка утрачены. Диаметр - 14 см, высота - 5,2 см. На стенках ковша, снаружи, присутствуют чеканные и гравированные сцены с участием реальных и фантастических животных. На дне ковша, в медальоне, - чеканное погрудное изображение святого воина Федора в доспехах, с копьем в правой руке и мечем в левой. По сторонам от Святого над-

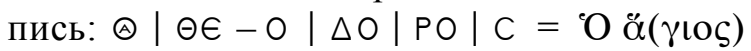

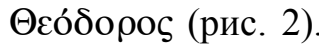

Будучи выдающимся произведением византийского ювелира, этот ковш неоднократно привлекал внимание исследователей, как отечественных [4, с. 314, ил. 205-207; 7, с. 197 , $201,262-263$, ил. $310,316,375$; 8, с. 119,123 , № $23 ; 10$, с. 88 , № 551; 34, p. 80] (нельзя не отметить, что все это работы каталожного типа), так и, в последнее время, зарубежных $[21$, p. $26-29$, fig. $1-3 ; 24$, p. $16-17 ; 25$, p. 193 , fig. 11-12; 32, p. 130-132, fig. 14-15] (это основные публикации, но список не исчерпывающий). Их интересовала преимущественно художественная составляющая, однако смысл и значение ансамбля изображений чудищ, животных, рыб и голых людей так и остались загадкой, несмотря на полные учености гипотезы и тонкие аналогии. Уникальный характер этого памятника также породил разнообразные мнения относительно его датировки и географической привязки, однако и в них больше категоричности, нежели обоснованности. Тем удивительнее, что имеющаяся на венчике ковша надпись не вызвала особого интереca, хотя и была неоднократно опубликована (не всегда без ошибок, несмотря на краткость и четкость) и переведена на русский и английский языки.

Вырезанная по кругу на вертикальном, чуть загибающемся наружу, плоском венчике надпись (рис. 2) гласит:

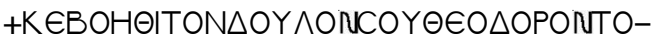

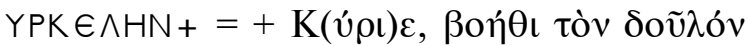

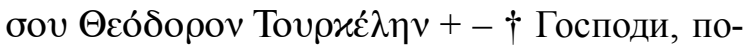
моги рабу твоему Феодору Туркелу $\uparrow$.

Формула надписи и ее орфографические особенности (итацизм, смешение $\omega$ и $\mathrm{O}$, впрочем, весьма умеренные) не выходят за обычные рамки средневизантийской эпиграфики. А вот ее палеография очень интересна. Все мачты, петли и многие диагональные элемен- 
ты выполнены двойными линиями, что типично для надписей на металле с ранневизантийского времени ${ }^{1}$ и восходит к александрийскому (или библейскому) унциалу. При этом формы отдельных букв маньеризованы. В одних $(\epsilon, \Theta, O, C)$ вторые линии волнообразные, в других $(H, N)$ перекладина дополнена ромбиком или заостренной разомкнутой петелькой.

Такая маньеризация букв встречается на «Филофеевской ставротеке» XI-XII вв. [4, c. 312 , № $195 ; 6$, с. $120-123$, № $8 ; 10$, с. 87 , № 549], однако там вторые линии изогнутые, а не волнообразные, а засечки на перекладинах еще не обрели объем. Ту же типологию букв демонстрируют и надписи на точно не датированных венцах спафарокандидата Романа и его супруги из Византийского музея в Афинах [36, p. 270-271, № 242], однако здесь засечки уже имеют форму ромбика или миндалины, правда на вертикальных гастах. Датировать такую маньеризацию сложно, однако, например, на относящемся к правлению Михаила VII Дуки (1057-1069) «кивории» св. Димитрия Солунского [6, с. 114-119, № 7; 10 , с. 85 , № $547 ; 12$, с. 308-310, табл. LXXXIII] в аналогичном шрифте с двойными линиями ее признаков еще нет. Поэтому надпись на ковше Феодора Туркела можно с осторожностью отнести к последней трети XI или XII веку.

Естественно, встает вопрос о том, кем друг другу приходятся оба Туркела.

Результаты. Датировки и печати, и ковша весьма широки и поэтому не могут способствовать разъяснению вопроса. Здесь мы неизбежно ступаем на зыбкую почву догадок и гипотетических построений.

Одно несомненно, что Туркел - это личное имя переводчика. В этом убеждает печать его коллеги - патрикия Сфена [33, p. 193 198, fig. 1]. Очевидно, что сочетание чуждого, необычного для византийца имени и должности гарантировало безошибочную идентификацию.

А вот владелец ковша Феодор именовался вторым именем Туркел как фамильным

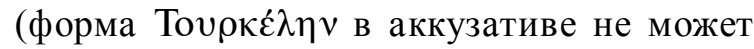
быть патронимиком). Таким образом, перед нами - еще один пример хорошо известного и повсеместно распространенного явления трансформации иностранных личных имен в родовые прозвища (на византийском материале изучено [19, р. 57-66]). Впрочем, судя по тому, что никаких других Туркелов в доступных нам византийских источниках, а также литературе и базах данных найти не удалось (такими сведениями не располагал, к примеру, и Дьюла Моравчик [27, р. 327]), носители этого имени были не слишком успешны во взращивании своего фамильного древа, а родовое имя, судя по датам памятников, могло не выйти за пределы второго поколения.

Наиболее вероятная этимология имени тюркская, его смысл - благопожелание (уже третье в нашем небольшом исследовании): «живи, новорожденный!» $[29, \text { p. 359, 794 }]^{2}$.

Не выглядит невозможным предположение, что Туркел стал ромеем в первом поколении. Находка двух его печатей в разных уголках Руси подталкивает к мысли о том, что его профессиональные обязанности были связаны именно с русским направлением политики Константинополя.

Что касается Феодора Туркела, можно предположить, что он был достаточно богат или занимал весомое положение в обществе, чтобы заказать или получить в подарок столь изящный и дорогой ковш. А то, что изображения на нем не поддаются расшифровке, скорее говорит в пользу того, что их смысл был понятен только самому владельцу и, возможно, узкому кругу близких людей. Поэтому вряд ли у него возникло бы желание расстаться со своим ковшом по доброй воле. Возьмем на себя смелость предположить, что он попал в Прикамье в результате каких-то чрезвычайных событий, возможно годы или даже века спустя после смерти владельца.

\section{ПРИМЕЧАНИЯ}

${ }^{1}$ Такой способ написания следует отличать от выполнения всех форм двойной линией, восходящего к рельефному шрифту.

${ }^{2}$ Версия грузинского посредства, которую выдвинул В.С. Кулешов [11, с. 364], больше отражает обширные лингвистические познания автора, нежели реальность, а утверждение о происхождении ковша из «области византийско-багратидскосельджукидского пограничья» переносит в область догадок, которые невозможно проверить. 


\section{ВИЗАНТИЙСКАЯ СФРАГИСТИКА}

\section{ПРИЛОЖЕНИЕ}
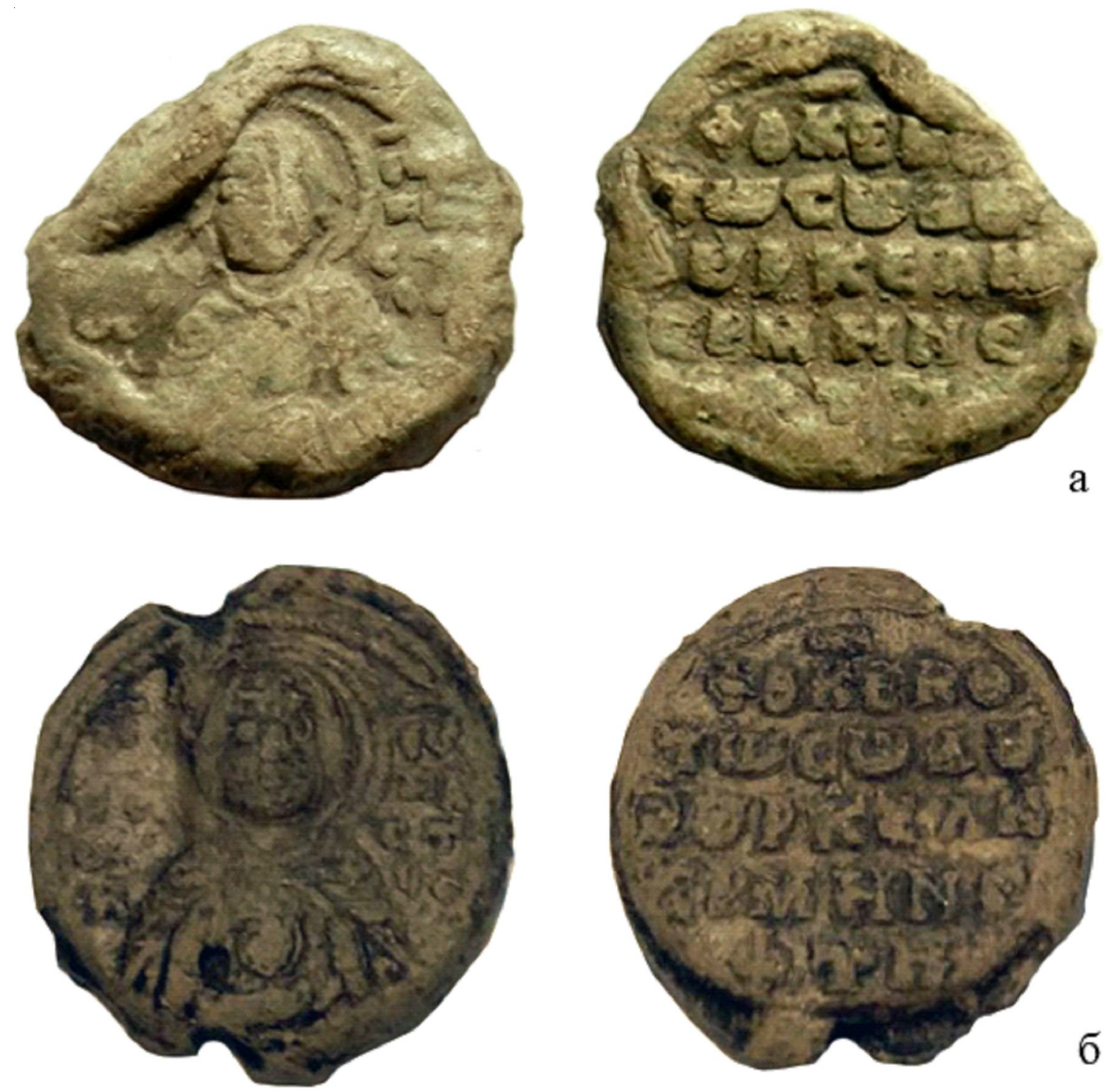

Рис. 1. Печати Туркела, переводчика (вторая половина XI в.)

Fig. 1. Seal of Turkel, translator (second half of the $11^{\text {th }}$ century) 
А.Ю. Виноградов, Д.В. Каштанов, В.Н. Чхаидзе. Туркелы - тюркская семья на византийской службе

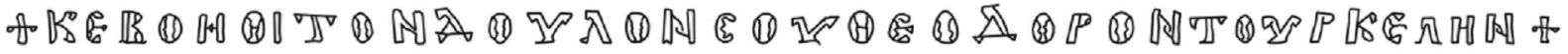
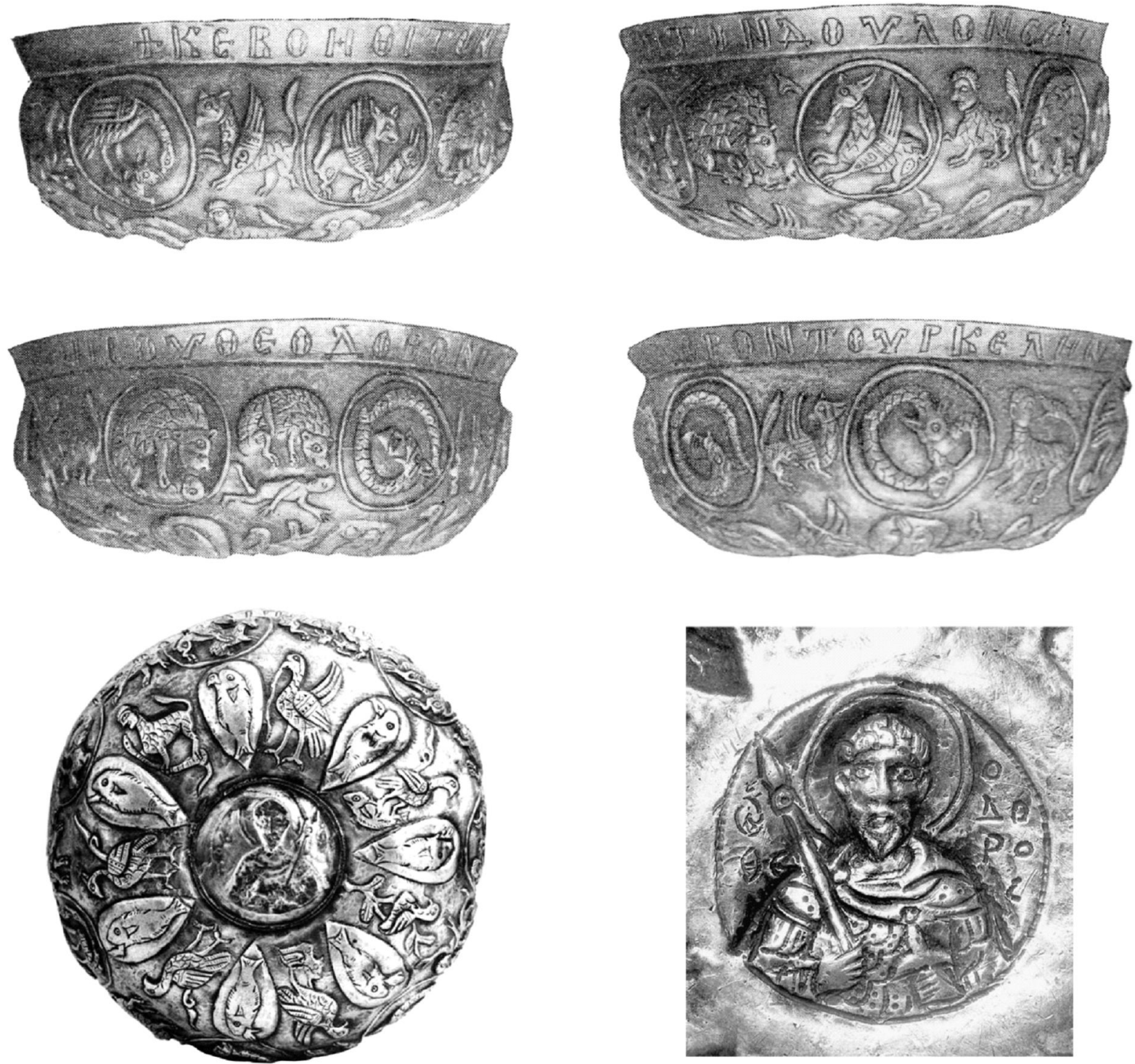

Рис. 2. Ковш Феодора Туркела и прорисовка надписи на нем (последняя треть XI - XII в.)

Fig. 2. The bucket of Theodore Turkel and the drawing of the inscription on it (last third of the $11^{\text {th }}-12^{\text {th }}$ centuries) 


\section{СПИСОК ЛИТЕРАТУРЫ}

1. Бадер, О. Н. Отчет об археологических раскопках и разведках, произведенных Камской археологической экспедицией Молотовского Госуниверситета в 1949 г. / О. Н. Бадер // Архив ИА РАН. -P-1. №384. -78 л.

2. Бадер, О. Н. Камская археологическая экспедиция в 1949 г. / О. Н. Бадер // Краткие сообщения Института истории материальной культуры. 1951. - Вып. 39. - С. 89-95.

3. Банк, А. В. Выставка византийских материалов в Государственном Эрмитаже / А. В. Банк // Византийский временник. - 1956. - Т. 11. - С. 340-348.

4. Банк, А. В. Византийское искусство в собраниях Советского Союза / А. В. Банк. - Л. ; М. : Сов. художник, 1966. -392 с.

5. Византийская сфрагистика в трудах В. С. Шандровской / под. ред. Е. В. Степановой. СПб. : Изд-во Гос. Эрмитажа, 2019. - 526 с.

6. Византийские древности. Произведения искусства IV-XV веков в собрании Музеев Московского Кремля : Каталог / отв. ред.-сост. И. А. Стерлигова. - М. : Пинакотека, 2012. - 608 с.

7. Даркевич, В. П. Светское искусство Византии. Произведения византийского художественного ремесла в Восточной Европе X-XIII века / В. П. Даркевич. - М. : Искусство, 1975. - 352 с.

8. Дьяконова, И. В. Искусство народов зарубежного Востока в Эрмитаже / И. В. Дьяконова. Л. : Изд-во Гос. Эрмитажа, 1962. - 128 с.

9. Ибн Халдун. Введение (ал-Мукаддима) / Ибн Халдун ; сост., пер. с араб. и примеч. А. В. Смирнова // Историко-философский ежегодник. - 20072008. -№ 1. - С. 187-217.

10. Искусство Византии в собраниях СССР. 2. Каталог выставки. Искусство эпохи иконоборчества. Искусство IX-XII веков / под ред. А. В. Банк и О. С. Поповой. - М. : Сов. художник, 1977. - 156 с.

11. Кулешов, Вяч. С. Серебро за меха из страны мрака: памятники византийской, восточной и западной торевтики и нумизматики в сакральной экономике югорского общества V-XV вв. / Вяч. С. Кулешов // Византия в контексте мировой культуры : материалы конф., посвящ. памяти Алисы Владимировны Банк (1906-1984) / науч. ред. В. Н. Залесская. - СПб. : Изд-во Гос. Эрмитажа, 2017. - С. 363372. - (Труды Государственного Эрмитажа ; T. LXXXIX).

12. Лихачев, Н. П. Моливдовулы греческого Востока / Н. П. Лихачев. - М. : Наука, 1991. - 359 с. (Научное наследство ; Т. 19).

13. Соколова, И. М. Богоматерь Одигитрия Влахернская из Успенского собора Московского Кремля / И. М. Соколова // Многоценное сокровище. Иконы Богоматери Одигитрии Влахернской в России / авт.- сост.: С. В. Гнутова, Г. В. Сидоренко, И. М. Соколова. -М. : Полиграф. центр «Декарт», 2005. - С. 23-29.

14. Трифонова, А. Икони от църквата «Преображение Господне» в Поморие (XV-XX в.). / А. Трифонова. - [Б. м.] : Рива, [б. д.]. - 248 с. - Электрон. текстовые дан. - Режим доступа: https:/www. academia.edu/25864375. - Загл. с экрана.

15. Филипчук, О. М. Печатка Михаїла, «пансеваста і великого перекладача варягів» / О. М. Филипчук // Сфрагістичний щорічник. - 2012. Вип. III. - С. 5-16.

16. Чхаидзе, В. Н. Византийская печать переводчика Икелия (вторая половина ХІ в.) / В. Н. Чхаидзе // IX Международный Византийский семинар

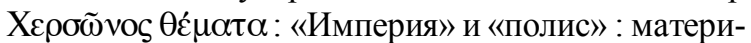
алы науч. конф. / отв. ред. Н. А. Алексеенко. - Севастополь : ООО «Колорит», 2017. - С. 124-127.

17. Шандровская, В. С. Византийские печати переводчиков / В. С. Шандровская // Одиннадцатая Всероссийская нумизматическая конференция : тез. докл. и сообщ. / отв. ред. А. С. Мельникова. - СПб. : Изд-во Гос. Эрмитажа, 2003. - С. 56-57.

18. Шандровская, В. С. Византийские печати переводчиков / В. С. Шандровская // Albo dies notanda lapillo : Коллеги и ученики - Г. Е. Лебедевой / отв. ред. В. А. Якубский. - СПб. : Алетейя, 2005. - C. 109-115.

19. Cheynet, J. C. Du prénom au patronyme: les étrangers à Byzance ( $\mathrm{X}^{\mathrm{e}}-\mathrm{XII} \mathrm{I}^{\mathrm{e}}$ siècles $) / \mathrm{J}$. C. Cheynet // Studies in Byzantine Sigillography. - 1987. - Vol. 1. P. 57-66.

20. Cotsonis, J. The Religious Figural Imagery of Byzantine Lead Seals. I. Studies on the Image of Christ, Virgin and Narrative Scenes / J. Cotsonis. London ; New York : Taylor \& Francis Group, 2020.xxvi, $314 \mathrm{p}$.

21. Frentrop, L. Protection and salvation : An eleventh-century silver vessel, its imagery, and its function / L. Frentrop // Byzantine and Modern Greek Studies. - 2018. - Vol. 42 (1). - P. 26-44.

22. Laurent, V. Le Corpus des sceaux de l'Empire Byzantin. Tome V, 2 : L'Église / V. Laurent. - Paris : Centre National de la Recherche Scietifique, 1965. $538 \mathrm{p}$.

23. Laurent, V. Le Corpus des sceaux de l'Empire Byzantin. Tome II: L'administration central / V. Laurent. - Paris : Centre National de la Recherche Scietifique, $1981 .-740 \mathrm{p}$.

24. Maguire, E. D. Other icons. Art and power in Byzantine secular culture / E. D. Maguire, H. Maguire. Princeton : University Press, 2007. - xxii, 201 p.

25. Maguire, $H$. The prophane aesthetic in Byzantine art and literature / H. Maguire // Dumbarton Oaks Papers. - 1999. - Vol. 53. - P. 189-205.

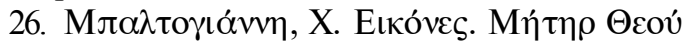

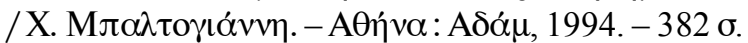


27. Moravcsik, G. Byzantinoturcica. 2. Sprachreste der Türkvölker in den Byzantinischen Quellen / G. Moravcsik. - Leiden : E.J. Brill, 1983. - 375 p.

28. Oikonomides, N. A. Collection of Dated Byzantine Lead Seals / N. A. Oikonomides. Washington : Dumbarton Oaks, 1986. - 175 p.

29. Rásonyi, L. Onomasticon Turcicum. Turkic personal names / L. Rásonyi, I. Baski. - Bloomington : Institute of Inner Asian Studies, 2007. - 836 p.

30. Seibt, W. Der Bildtypus der Theotokos Nikopoios. Zur Iconographie der Gottermutterikone, die 1030/31 in der Blachemenkirche wiederaufgefimden wurde /W. Seibt // Buگavtıvó. - 1985. - T. 13.-P. 549-565.

31. Seibt, W. Die Darstellung der Theotokos auf byzantinischen Bleisiegeln, besonders im 11 . Jahrhundert / W. Seibt // Studies in Byzantine Sigillography. - 1987. - Vol. 1. - P. 35-56.

32. Ševčenko, N. P. Eaten alive : Animal attacks in the Venice Cynegetica / N. P. Ševčenko // Z $\omega \alpha \kappa \alpha$ ı

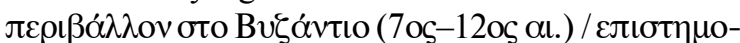

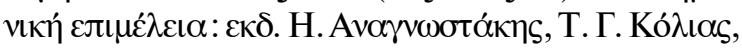

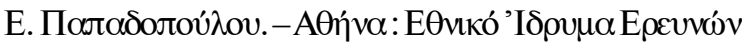

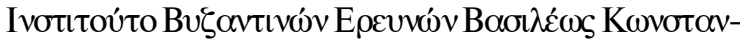

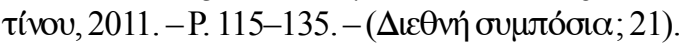

33. Shchavelev, A. A Seal of Byzantine "Translator of the English" Patrikios Sphen : Its Date and SocioCultural Context / A. Shchavelev // Byzantine and Rus' Seals. Proceedings of the International Colloquium on Rus'-Byzantine Sigillography / eds. H. Ivakin, N. Khrapunov, W. Seibt. - Kyiv : Sheremetievs' Museum, 2015. - P. 193-200.

34. Sinai. Byzantium. Russia. Orthodox art from the sixth to the twentieth century / Ed. by Yu. Piatnitsky. - London ; St. Petersburg : Saint Catherine Foundation, 2000. - 488 p.

35. The Cambridge Grammar of Medieval and Early Modern Greek. Vol. 1. General Introduction and Phonology / D. Holton, G. Horrocks, M. Janssen, T. Lendari, I. Manolessou, N. Toufexis. - Cambridge : Arts and Humanities Research Council; Cambridge University Press, 2019. - clxx, 237 p.

36. The World of the Byzantine Museum / ed. by F. Boubouli. - Athens : Byzantine and Christian Museum Publ., 2004. - 509 p.

37. Weyl Carr, A. Taking place: the shrine of the Virgin veiled by God in Kalopanagiotis, Cyprus / A. Weyl Carr // Иеротопия. Создание сакральных пространств в Византии и Древней Руси / под ред. А. М. Лидова. М. : Прогресс-Традиция, 2006. - С. 388-408.

\section{REFERENCES}

1. Bader O.N. Otchet ob arkheologicheskikh raskopkakh i razvedkakh, proizvedennykh Kamskoy arkheologicheskoy ekspeditsiey Molotovskogo
Gosuniversiteta v 1949 g. [Report on the archaeological excavations and explorations made by the Kama archaeological expedition of Molotov state University in 1949]. Archive IA RAS, R-1, № 384. 781.

2. Bader O.N. Kamskaya arkheologicheskaya ekspeditsiya v 1949 g. [Kama archaeological expedition in 1949 year]. Kratkie soobshcheniya Instituta istorii materialnoy kultury [Brief reports of the Institute of the history of material culture], 1951, vol. 39, pp. 89-95.

3. Bank A.V. Vystavka vizantiyskikh materialov v Gosudarstvennom Ermitazhe [Exhibition of Byzantine materials in the State Hermitage]. Vizantiiskii vremennik, 1956, vol. 11, pp. 340-348.

4. Bank A.V. Vizantiyskoe iskusstvo v sobraniyakh Sovetskogo Soyuza [Byzantine art in the collections of the Soviet Union]. Leningrad; Moscow, Sovetskiy khudozhnik Publ., 1966. 392 p.

5. Stepanova E.V., ed. Vizantiyskaya sfragistika v trudakh V.S. Shandrovskoy [Byzantine sphragistics in the works of V.S. Shandrovskaya]. St. Petersburg, State Hermitage Publ., 2019. 526 p.

6. Sterligova I.A., ed. Vizantiyskie drevnosti. Proizvedeniya iskusstva $I V-X V$ vekov v sobranii Muzeev Moskovskogo Kremlya: Katalog [Byzantine antiquities. Works of art of the IV-XV centuries in the collection of the Moscow Kremlin Museums: Catalog]. Moscow, Pinakoteka Publ., 2012. 608 p.

7. Darkevich V.P. Svetskoe iskusstvo Vizantii. Proizvedeniya vizantiyskogo khudozhestvennogo remesla $v$ Vostochnoy Evrope X-XIII veka [Secular art of Byzantium. Works of Byzantine art craft in Eastern Europe of the X-XIII century]. Moscow, Iskusstvo Publ., 1975. 352 p.

8. Dyakonova I.V. Iskusstvo narodov zarubezhnogo Vostoka $v$ Ermitazhe [Art of the peoples of the foreign East in the Hermitage]. Leningrad, Izdatelstvo Gosudarstvennogo Ermitazha Publ., 1962. 128 p.

9. Smirnova A.V., ed. Ibn Haldun. Vvedenie (alMukaddima) [Introduction (al-Muqaddimah)]. Istorikofilosofskiy ezhegodnik [Historical and philosophical Yearbook], 2007-2008, no. 1, pp. 187-217.

10. Bank A.V., Popova O.S., eds. Iskusstvo Vizantii v sobraniyakh SSSR. 2. Katalog vystavki. Iskusstvo epokhi ikonoborchestva. Iskusstvo IX-XII vekov [Art of Byzantium in the collections of the USSR. 2. Catalogue of the exhibition. Art of the iconoclastic era. The art of the IX-XII centuries]. Moscow, Sovetskiy khudozhnik Publ., 1977. 156 p.

11. Kuleshov V. S. Serebro za mekha iz strany mraka: pamyatniki vizantiyskoy, vostochnoy i zapadnoy torevtiki i numizmatiki v sakralnoy ekonomike yugorskogo obshchestva V-XV vv. [Silver for furs from the land of darkness: monuments of Byzantine, Eastern and Western torevtics and numismatics in the sacred economy of the Yugor society of the V- 
XV centuries]. Zalesskaya V. N., ed. Vizantiya $v$ kontekste mirovoy kultury. Materialy konferentsii, posvyashchennoy pamyati Alisy Vladimirovny Bank (1906-1984) [Byzantium in the context of world culture. Materials of the conference dedicated to the memory of Alice Vladimirovna Bank (1906-1984)]. St. Petersburg, Izdatelstvo Gosudarstvennogo Ermitazha Publ., 2017, pp. 363-372. (Trudy Gosudarstvennogo Ermitazha [Works of the State Hermitage Museum]; vol. 89).

12. Likhachev N.P. Molivdovuly grecheskogo Vostoka [Molyvdovoula the Greek East]. Moscow, Nauka Publ., 1991. 359 p. (Nauchnoe nasledstvo [The Scientific legacy]; vol. 19).

13. Sokolova I.M. Bogomater Odigitriya Vlakhernskaya iz Uspenskogo sobora Moskovskogo Kremlya [Our lady Odigitria of Blachernae from the assumption Cathedral of the Moscow Kremlin]. Gnutova S.V., Sidorenko G.V., Sokolova I.M., eds. Mnogotsennoe sokrovishche. Ikony Bogomateri Odigitrii Vlakhernskoy v Rossii [A valuable treasure. Icons of our lady of Odigitria of Blachernae in Russia]. Moscow, Poligraficheskiy tsentr «Dekart» Publ., 2005, pp. 23-29.

14. Trifonova A. Ikoni ot crkvata «Preobrazhenie Gospodne» v Pomorie ( $X V-X X$ v.) [Icons from the Church "Transfiguration of the Lord" in Pomorie (XVXX-century)]. S.l., Izdatelstvo "Riva" Publ., s.a. 248 p. URL: https://www.academia.edu/25864375.

15. Filipchuk O.M. Pechatka Mihaïla, "pansevasta i velikogo perekladacha varjagiv" [Seal of Michael, "pansebastos and great translator of varangs"]. Sfragistichnij shhorichnik [Shgragistics yearbook], 2012, vol. III, pp. 5-16.

16. Chkhaidze V.N. Vizantiyskaya pechat perevodchika Ikeliya (vtoraya polovina XI v.) [The Byzantine seal of the translator Ikelia (the second half of the XI century)]. Alekseenko N. A., ed. IX Mezhdunarodnyy Vizantiyskiy seminar Chersōnos themata: «imperiya» $i$ «polis». Materialy nauchnoy konferentsii [IX International Byzantine seminar Chersōnos themata: "Empire" and "Polis". Materials of the scientific conference]. Sevastopol, OOO Kolorit Publ., 2017, pp. 124-127.

17. Shandrovskaya V.S. Vizantiyskie pechati perevodchikov [Byzantine seals of translators]. Melnikova A. S., ed. Odinnadtsataya Vserossiyskaya numizmaticheskaya konferentsiya. Tezisy dokladov $i$ soobshcheniy [Eleventh All-Russian numismatic conference. Abstracts of reports and messages]. Saint Petersburg, Izdatelstvo Gosudarstvennogo Ermitazha Publ., 2003, pp. 56-57.

18. Shandrovskaya V.S. Vizantiyskie pechati perevodchikov [Byzantine seals of translators]. Yakubskiy V.A., ed. Albo dies notanda lapillo: kollegi i ucheniki - G.E. Lebedevoy [Albo dies notanda lapillo: colleagues and students G.E. Lebedeva]. Saint Petersburg, Aletheia Publ., 2005, pp. 109-115.

19. Cheynet J.C. Du prénom au patronyme: les étrangers à Byzance $\left(\mathrm{X}^{\mathrm{e}}-\mathrm{XII}{ }^{\mathrm{e}}\right.$ siècles). Studies in Byzantine Sigillography, 1987, vol. 1, pp. 57-66.

20. Cotsonis J. The Religious Figural Imagery of Byzantine Lead Seals I. Studies on the Image of Christ, Virgin and Narrative Scenes. London; New York, Taylor \& Francis Group, 2020. xxvi, 314 p.

21. Frentrop L. Protection and salvation: an eleventh-century silver vessel, its imagery, and its function. Byzantine and Modern Greek Studies, 2018, vol. 42 (1), pp. 26-44.

22. Laurent V. Le Corpus des sceaux de l'Empire Byzantin. T. V, 2: L'Église. Paris, Centre National de la Recherche Scietifique, 1965. 538 p.

23. Laurent V. Le Corpus des sceaux de l'Empire Byzantin. T. II: L'administration central. Paris, Centre National de la Recherche Scietifique, 1981. 740 p.

24. Maguire E. D., Maguire H. Other icons. Art and power in Byzantine secular culture. Princeton, University Press, 2007. xxii, $201 \mathrm{p}$.

25. Maguire H. The prophane aesthetic in Byzantine art and literature. Dumbarton Oaks Papers, 1999, vol. 53, pp. 189-205.

26. Mpaltogiannē Ch. Eikones. Mètēr Theou [Icons. Mother of God]. Athens, Adam Publ., 1994. $382 \mathrm{p}$.

27. Moravcsik G. Byzantinoturcica. 2. Sprachreste der Türkvölker in den Byzantinischen Quellen. Leiden, E.J. Brill, 1983. 375 p.

28. Oikonomides N. A. Collection of Dated Byzantine Lead Seals. Washington, Dumbarton Oaks, 1986. 175 p.

29. Rásonyi L., Baski I. Onomasticon Turcicum. Turkic personal names. Bloomington, Institute of Inner Asian Studies, 2007. 836 p.

30. Seibt W. Der Bildtypus der Theotokos Nikopoios. Zur Iconographie der Gottermutterikone, die 1030/31 in der Blachemenkirche wiederaufgefimden wurde. Byzantina, 1985, vol. 13, pp. 549-565.

31. Seibt W. Die Darstellung der Theotokos auf byzantinischen Bleisiegeln, besonders im 11. Jahrhundert. Studies in Byzantine Sigillography, 1987, vol. 1, pp. 35-56.

32. Ševčenko N. P. Eaten alive: animal attacks in the Venice Cynegetica. Anagnōstakēs Ē., Kolias T.G., Papadopolou E., eds. Zōa kai periballon sto Byzantio (7os - 12os ai) [Animals and environment in Byzantium $\left.\left(7^{\text {th }}-12^{\text {th }} c.\right)\right]$. Athens, Ethniko Idryma Ereunōn Institouto Byzantinōn Ereunōn Basileōs Kōnstantinou Publ., 2011, pp. 115-135. (Diethnē symposia [International symposia]; vol. 21).

33. Shchavelev A. A Seal of Byzantine "Translator of the English" Patrikios Sphen: Its Date and Socio- 
А.Ю. Виноградов, Д.В. Каштанов, В.Н. Чхаидзе. Туркелы-тюркская семья на византийской службе

Cultural Context. Ivakin H., Khrapunov N., Seibt W., eds. Byzantine and Rus' Seals. Proceedings of the International Colloquium on Rus'-Byzantine Sigillography. Kyiv, Sheremetievs' Museum, 2015, pp. 193-200.

34. Piatnitsky Yu., ed. Sinai. Byzantium. Russia. Orthodox art from the sixth to the twentieth century. London, St. Petersburg, Saint Catherine Foundation, 2000. 488 p.

35. Holton D, Horrocks G., Janssen M., Lendari T., Manolessou I., Toufexis N., eds. The Cambridge Grammar of Medieval and Early Modern Greek. Vol. 1. General Introduction and Phonology.
Cambridge, Arts and Humanities Research Council; Cambridge University Press, 2019. clxx, 237 p.

36. Boubouli F., ed. The World of the Byzantine Museum. Athens, Byzantine and Christian Museum Publ., 2004. 509 p.

37. Weyl Carr A. Taking place: the shrine of the Virgin veiled by God in Kalopanagiotis, Cyprus. Lidov A.M., ed. Ierotopiya. Sozdanie sakralnykh prostranstv v Vizantii i Drevney Rusi [Eurotopia. Creating sacred spaces in Byzantium and Ancient Russia]. Moscow, «Progress-Traditsiya» Publ., 2006, pp. 388-408.

\section{Information About the Authors}

Andrey Yu. Vinogradov, Candidate of Sciences (History), Doctor of Sciences (Philology and Linguistics), Associate Professor, Senior Researcher, National Research University Higher School of Economics, Staraya Basmannaya St, 21/4, Bld. 3, 105066 Moscow, Russian Federation, auvinogradov@hse.ru, https://orcid.org/0000-0002-9516-6534

Denis V. Kashtanov, Independent Researcher, Moscow, Russian Federation, kastanon@gmail.com, https://orcid.org/0000-0001-7273-5717

Viktor N. Chkhaidze, Candidate of Sciences (History), Researcher, Institute of Archaeology of the Russian Academy of Sciences, Dm. Ulyanova St, 19, 117036 Moscow, Russian Federation, chkhaidze@yandex.ru, https://orcid.org/0000-0003-0806-6218

\section{Информация об авторах}

Андрей Юрьевич Виноградов, кандидат исторических наук, доктор филологических наук, доцент, старший научный сотрудник, Национальный исследовательский университет «Высшая школа экономики», ул. Старая Басманная, 21/4, стр. 3, 105066 г. Москва, Российская Федерация, auvinogradov@hse.ru, https://orcid.org/0000-0002-9516-6534

Денис Викторович Каштанов, независимый исследователь, г. Москва, Российская Федерация, kastanon@gmail.com, https://orcid.org/0000-0001-7273-5717

Виктор Николаевич Чхаидзе, кандидат исторических наук, научный сотрудник, Институт археологии РАН, ул. Дм. Ульянова, 19, 117036 г. Москва, Российская Федерация, chkhaidze@yandex.ru, https://orcid.org/0000-0003-0806-6218 